\title{
AN ESTIMATING METHOD OF WORKER'S TASK WITH 6-DOF SENSORS
}

\author{
Soungho Chae ${ }^{1)}$, Naruo Kano ${ }^{2)}$ \\ 1) Advanced Research Institute for Science and Engineering, Waseda University, Tokyo, \\ Japan, Visiting Assistance Professor, Ph.D. \\ 2) Department of Architecture, Waseda University, Tokyo, Japan, Professor, Dr.Eng. \\ chae@waseda.jp
}

\begin{abstract}
Recently construction workers tend to work alone and are getting older. In such working atmosphere, monitoring their works at the site is necessary for keeping task performance quality and accuracy. However, the management and evaluation of workers' performance can only be done by supervisors' physical observation. Understanding of their works will be easier if the data that shows what kind of task is performed can be estimated from their body positions and movement, and that enable monitoring by data obtained concurrently.

Data for body positions and movements of workers was obtained and measured by using 6-DOF motion sensors, and the method to estimate the type of task by using neural network is described. Finally the authors developed the method to monitor the work at the site using the data obtained by 6-DOF motion sensors and systemized the estimation procedure.
\end{abstract}

Keywords: 6-DOF sensor, estimation, worker's task, monitoring

\section{INTRODUCTION}

In recent years, because of high demand of efficient use of human resource, workers tend to work alone. Moreover, workers are getting older, so possibility of accident at site during work time arises in concern. Tasks done by single worker are expected to increase. In such working atmosphere, continuous monitoring of each of worker's action is necessary in order to maintain high quality of performance management. But evaluation of works have been able to only be made by supervisors' physical observation, and it is impossible to understand workers concurrent performance all over the construction site at once.

Site management becomes more efficient by gathering and evaluating data obtained from monitoring workers. The date collected from monitoring shows various positions and movements of workers' tasks. Moreover, the systematic process established for evaluation of collected data should become the method of concurrent monitoring.

The analysis of on-site construction works is made by many. Tamura [1] suggested suitability of improved therblig to the construction works. Mine [2] suggested the method of measuring working time on reinforced concrete placement work and presented time study evaluation result. Kobayashi [3] worked on research for symptoms of worker fatigue in chimney construction. Kano [4] developed five evaluation models for selecting among alternate methods based on past construction records and studied the reliability of the models.

The authors [5] have suggested the method to measure positions and movements of workers and develop into 6-DOF data to estimate workers' task and showed effectiveness of the method.

The objective of this research is to develop automated estimation process, and system for monitoring works real time. Prototype was made based on the developed system and experiment are undertaken for reliability of the system to examine effectiveness of the system. In addition, suitability of use of this device and program for various workers are tested.

\section{MONITORING SYSTEM DESIGN}

Monitoring system design is composed by 5 parts: 1) Collection of the body position and movement data, 2) Computation of the feature parameters, 3) Calculation for the neural network outputs, 4) Selection of the type of task, 5) Monitoring of the selected task in each time unit, as in Figure 1, according to the method to estimate worker's task.

The design is intended to collect data and output the estimated result. At first, the body position and movement data is collected from three 6-DOF sensors and forms a list. Then some part of the data in the list is extracted for designated time period and used for computation of feature parameters. The parameter is used as input for neural network, and recognized value, output, is derived throughout the calculation.

Process of monitoring system starts from Data collection from 6-DOF. Three 6-DOF sensors are used to collect data and establish list. Then at calculation of recognition value, the data is extracted from the list by designated time interval and find out feature parameters. Using these parameters as input 
for neural network, and develop recognition value as output. At making list of recognition value, recognition value is taken for various unit times into the list. Finally at Evaluation of overall selection of task, mean value and standard deviation for recognition value are calculated and compared for each task, then examine the content of works to establish the final estimated result.

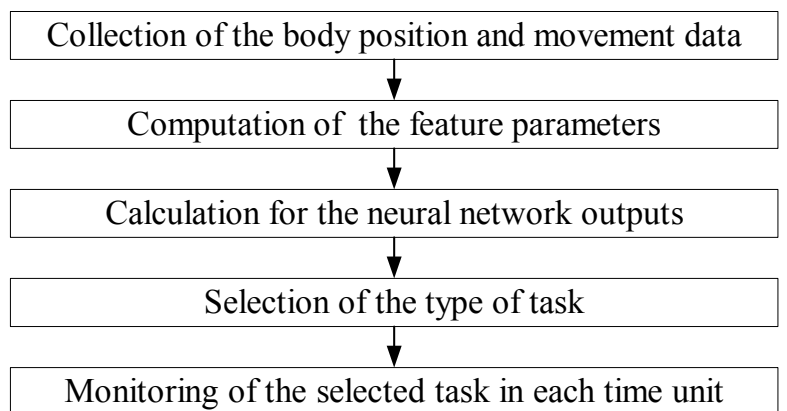

Figure 1. Monitoring system flow

\section{ESTIMATION OF WORKER'S TASK}

\subsection{COLLECTION OF THE BODY POSITION AND MOVEMENT DATA FROM 6-DOF MOTION SENSORS}

The sensors in navigation of robots and unmanned vehicles was used to collect 6-DOF data of body position and movement. (Table 1) 6-DOF data composed by 3-axis accelerations and 3-axis orientation in 3 dimensions. (Figure 2)

Table 1. 6-DOF sensor specification

\begin{tabular}{c|c}
\hline \multirow{2}{*}{ Component } & $\begin{array}{l}3 \text { accelerometer sensors } \\
3 \text { magnetometer sensors } \\
3 \text { rate gyroscope sensors }\end{array}$ \\
\hline Weight & $40 \mathrm{~g}$ \\
\hline Size & $64 \mathrm{~mm}$ by $90 \mathrm{~mm}$ by $25 \mathrm{~mm}$ \\
\hline Output Data Rate & $20 \mathrm{~Hz}$ \\
\hline Supply Voltage & $9 \mathrm{vdc}$ \\
\hline Connectors & RS-485
\end{tabular}

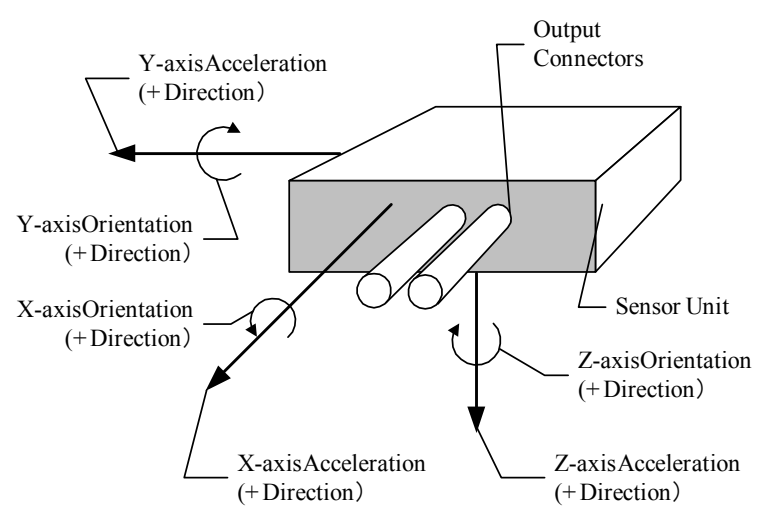

Figure 2. 6-DOF sensor coordinates

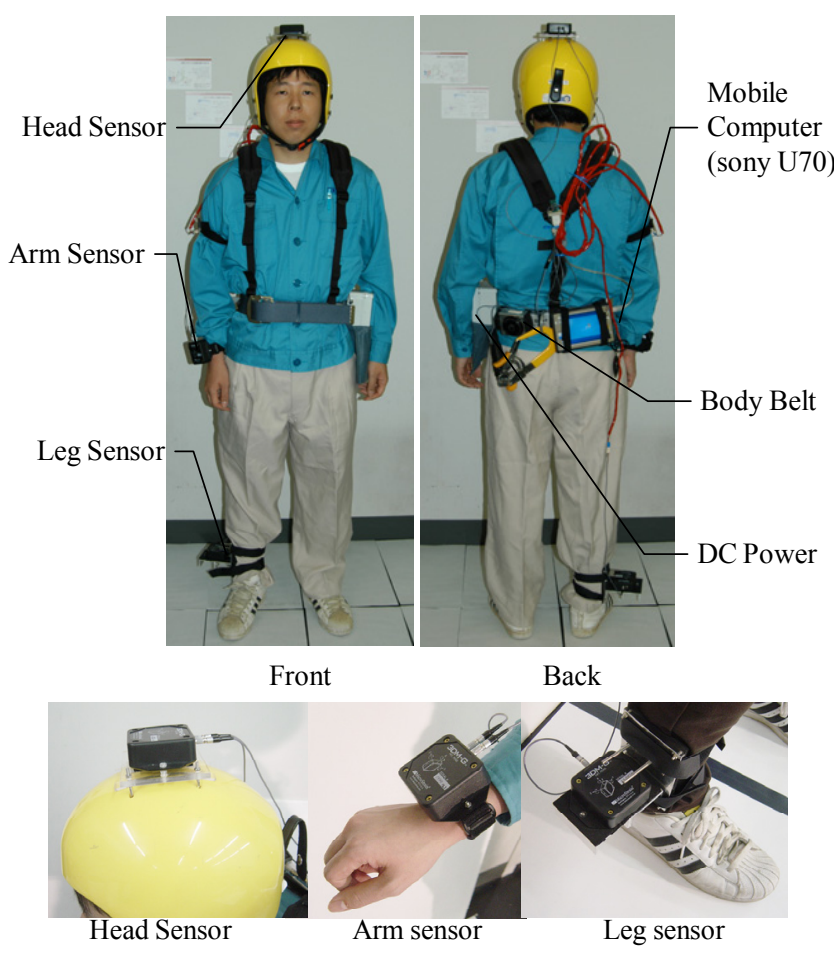

Figure 3. Device of monitoring system

The authors examined the body parts for equipments, the 6-DOF sensors. And the body parts were determined as three places: head, arm, leg, for the following reasons.

a. The positions which data can be acquired for the feature of a working posture as 6-DOF data.

b. The positions which sensors do not interfere worker's tasks.

c. The positions which wearing and removal of the sensors in the work site are easy.

The head sensor is fixed on the helmet with the bolts, and the data for changes of position of head from bending and stretching back or twisting the body is collected. The arm sensor is attached with the Velcro tape on the wrist of a dominant hand, and the data for arm, such as operation of a tool and handling parts, is collected. The leg sensor is fixed to the stand attached above right ankle with the bolts, and the data for leg, such as walking, sitting down, stepping on something, is collected. (Figure 3)

\subsection{COMPUTATION OF FEATURE PARAMETERS}

The data collected from 6-DOF sensors include value of angle changed from movement of the worker's body. Therefore, if a worker's body rotates, the data inputted becomes a value which is different from previous one even if the same type of task is being done. However, when worker is doing the same task, different value may be derived if the worker is facing to the different direction. Accuracy of the estimate improves by use of the data which the effect by the body direction was removed. 
Table 2. Feature parameters

\begin{tabular}{|c|c|c|c|}
\hline Feature Parameters & Equation & Definition & Index \\
\hline $\operatorname{Avr}\left(H_{(A-B)_{i}}\right)$ & $\frac{\sum_{i=1}^{i=n} H_{(A-B)_{i}}}{n}$ & $\begin{array}{l}\text { Mean value of } \\
\text { correlation of sensor-A } \\
\text { orientation and sensor-B } \\
\text { orientation }\end{array}$ & $\begin{array}{l}\operatorname{Avr}\left(H_{(A-B)_{i}}\right): \text { Mean of the } \\
\quad \text { variables } H_{(A-B)_{i}} \\
\operatorname{Std}\left(H_{(A-B)_{i}}\right): \text { Standard deviation of }\end{array}$ \\
\hline $\operatorname{Std}\left(H_{(A-B)_{i}}\right)$ & $\sqrt{\frac{n \sum_{i=1}^{i=n}\left(H_{(A-B)_{i}}\right)^{2}-\left(\sum_{i=1}^{i=n} H_{(A-B) i}\right)^{2}}{n^{2}}}$ (2) & $\begin{array}{l}\text { Standard deviation of } \\
\text { correlation of sensor-A } \\
\text { orientation and sensor- } \\
\text { Borientation }\end{array}$ & $\begin{array}{r}\text { variables } H_{(A-B)_{i}} \\
\operatorname{Sy}\left(H_{(A-B)_{i+1}}-H_{(A-B)_{i}}\right): \text { Sum of the } \\
\text { variables }\left(H_{(A-B)_{i+1}}-H_{(A-B)_{i}}\right)^{2} \\
\operatorname{Sy}\left(T_{(A)_{i}}\right): \text { Sum of variables }\left(T_{(A)_{i}}\right)^{2}\end{array}$ \\
\hline $\operatorname{Sy}\left(H_{(A-B)_{i+1}}-H_{(A-B)_{i}}\right)$ & $\sum_{i=1}^{i=n}\left(H_{(A-B)_{i+1}}-H_{(A-B)_{i}}\right)^{2}$ & $\begin{array}{l}\text { Variation of correlation } \\
\text { of sensor-A orientation } \\
\text { and sensor-B orientation }\end{array}$ & $\begin{array}{l}H_{(A-B)_{i}}: \text { Difference of orientation between } \\
\quad \text { sensor - A to sensor - B at time(i) } \\
T_{(A)_{i}}: \text { Differenc of acceleration } \\
\quad \text { from time(i) to time }(\mathrm{i}+1)\end{array}$ \\
\hline $\operatorname{Sy}\left(T_{(A)_{i}}\right)$ & $\sum^{i=n}\left(T_{(A)_{i}}\right)^{2}$ & $\begin{array}{l}\text { Variation of velocity } \\
\text { of sensor-A }\end{array}$ & $\begin{array}{l}n: \text { Numbers of output data } \\
\mathrm{i}: \text { Time of data ouput }(i=1,2, \cdots \cdot, n) \\
A, B: \text { Name of two sensors }\end{array}$ \\
\hline
\end{tabular}

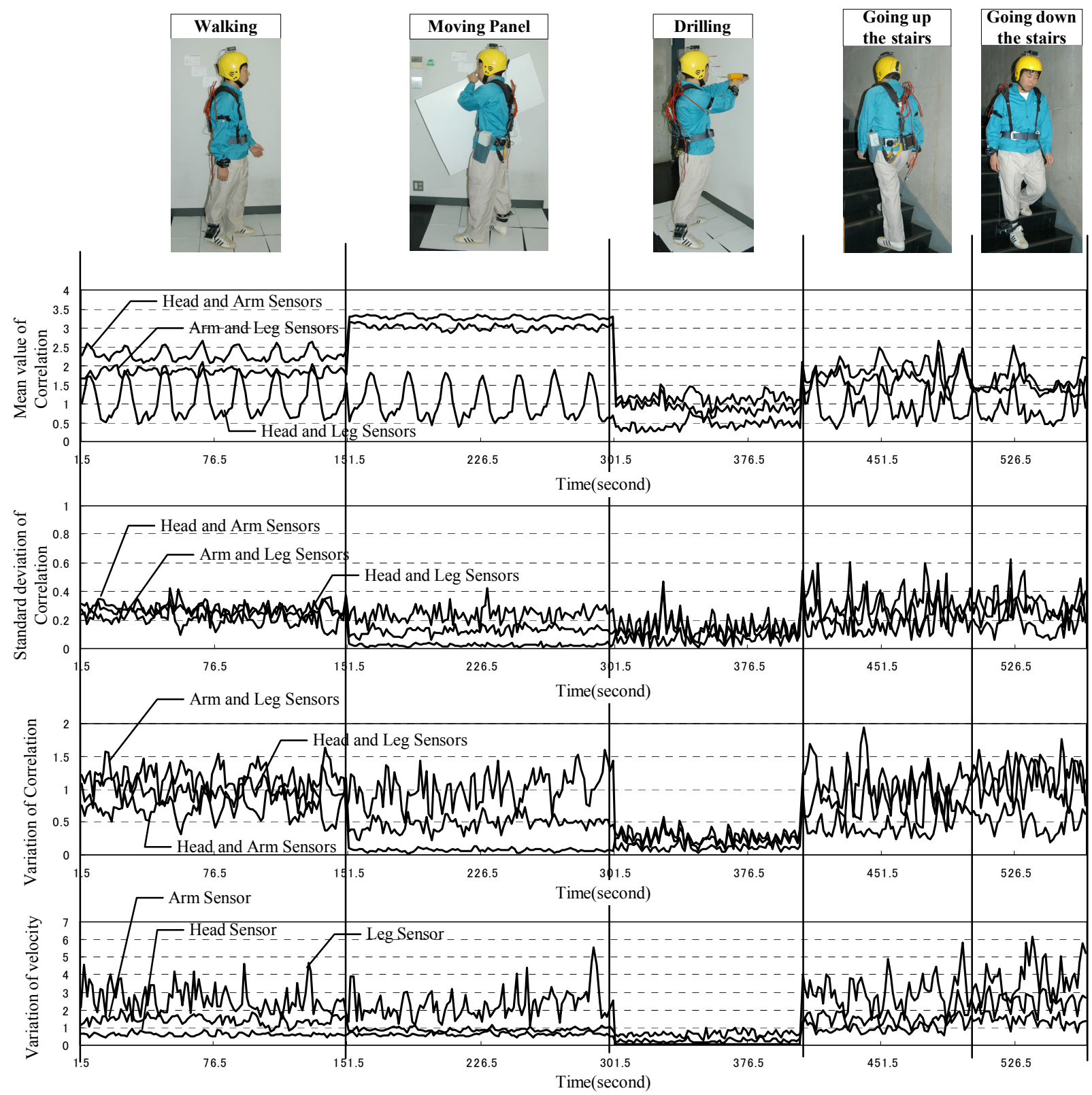

Figure 4. An example of the computed feature parameters (time unit is $1.5 \mathrm{sec}$.) 
In order to remove such effect, the authors computed feature parameters according to the relationship between 6-DOF data and body position and movement.

Feature parameters are the mean value of correlation of sensor-A orientation and sensor-B orientation in each time unit computed using 3-axis orientation data Eq. (1), the standard deviation Eq. (2), and the variation Eq. (3), and are the variation of velocity of sensor-A in each time unit computed using 3-axis acceleration data Eq. (4). (Table 2)

Correlation of orientation between sensor-A and sensor-B is inner product of unit vector for sensor-A and sensor-B $\left(H_{(A-B) i}\right)$. Three-axis orientation data is translated into unit vector in 3-dimensional position coordinates. Feature parameters are computed by using product of inner vectors.

The mean value of the inner product of unit vector for sensor-A and sensor-B in each time unit $\left(A v r\left(H_{(A-B) i}\right)\right)$, standard deviation $\left(\operatorname{Std}\left(H_{(A-B) i}\right)\right)$, and the sum of squared difference value from time $(i)$ to time $(i+1)\left(S y\left(H_{(A-B) i+1}-H_{(A-B) i}\right)\right)$ are feature parameters.

The variation of velocity of sensor-A is difference of accelerations from time $(i)$ to time $(i+1)$. The sum of squared value $\left(\operatorname{Sy}\left(T_{(A) i}\right)\right.$ is another feature parameter.

"Walking", "Moving panel”, "Drilling”, "going up the stairs", and "going down stairs" were used as experimental work. Then the feature parameters of 6 -DOF data were collected. The result was plotted in figures (Figure 4) and that shows typical sequential patterns exist, which corresponds to each task performed by the worker.

For example, as a result of comparing feature parameters of "Walking" and "Moving panel" turned out that there are little variations of correlation of head and arm sensors of "Moving panel" and even the velocity of motion of arm sensor.

Moreover, since the motion of head and leg of the worker who performs "Moving panel" and "walking" is alike, the variation of correlation of head and leg sensors and the velocity of movement shows approximately the same patterns.

\subsection{CALCULATION FOR THE NEURAL NETWORK OUTPUTS}

The neural network is applied to the method of the recognition of tasks by feature parameters. Its model is designed in the three-layered Back-propagation network with the standard connections.

The recognition value, which shows the degree that suits each composition and operated from 0 to 1 , was outputted using 12 feature parameters computed from 6-DOF data from the head sensor, the arm sensor, and the leg sensor as an input value of the neural network.

The feature parameters set for training neural network are collected by making the worker repeats tasks for the whole time units to estimate. The worker is equipped with the device of the monitoring system. The carried-out tasks were videotaped, and each of that feature parameters sets are named for every task. The inputs neural value for training the network is set to the feature parameters, and the outputs neural value is set to the name of tasks.

\subsection{SETTING OF TIME UNIT FOR RECOGNITION}

Several time units were set for different types of task because each task has own suitable time length for recognition. Since a time unit contains two or more tasks, the range of the time unit for calculating the feature parameters is longer and the probability of the error to an estimation value becomes high.

Moreover, since the amount of data which calculates the feature parameters decreases and the values are greatly influenced by each motion in tasks, when the range of the time unit for calculating the feature parameters is short.

Therefore, the authors set for several time units according to type of works for recognition. The minimum time unit is set for the task which requires minimum amount of time. The minimum range of the time unit is multiplied until it matches the maximum time of the task. The number of the time units from the maximum range to the minimum range is the sum of the total numbers of the time unit for recognition. This monitoring system, authors set the time range from " 1.5 seconds" to "4.5 seconds". At " 1.5 seconds", the minimum time range, 10 outputs in the range collected from sensors are used to calculate the feature parameters. "4.5 seconds" and "3 seconds" are set up as the other time units, too.

For other time units, the " 3 seconds" and the " 4.5 seconds" delayed by the minimum time units of 1.5 seconds from the start are also set. Since the start delay is for making the data of the feature parameters of the time units the optimal, no matter what time a task is started. (Figure 5)

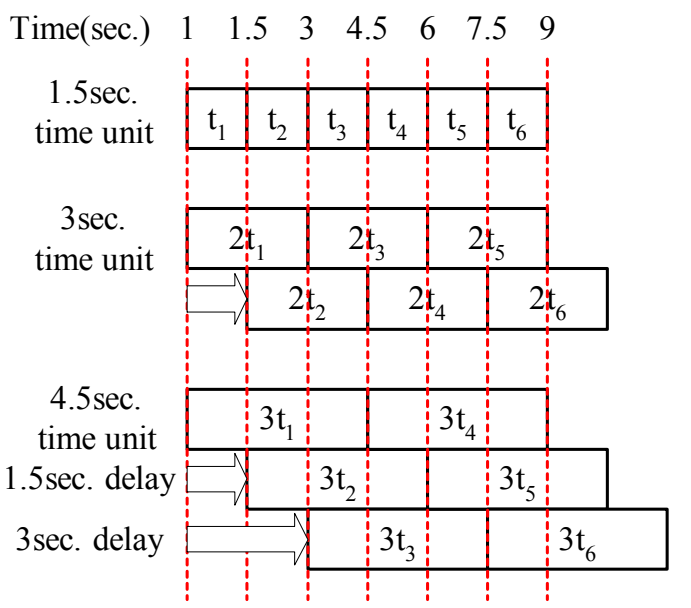

Figure 5. Setting of several time units for recognition 


\subsection{MONITORING OF THE SELECTED TASK IN EACH TIME UNIT}

Six recognition values of the in each task are outputted from the outputs neural for the every time units. As a method of selecting the result of reliable monitoring from the six recognition values, the authors use the statistics value of the recognition values. The mean value of the recognition values is close to " 1 " and there are few deviations in each time unit becomes the measure which the task is selected as result of monitoring.

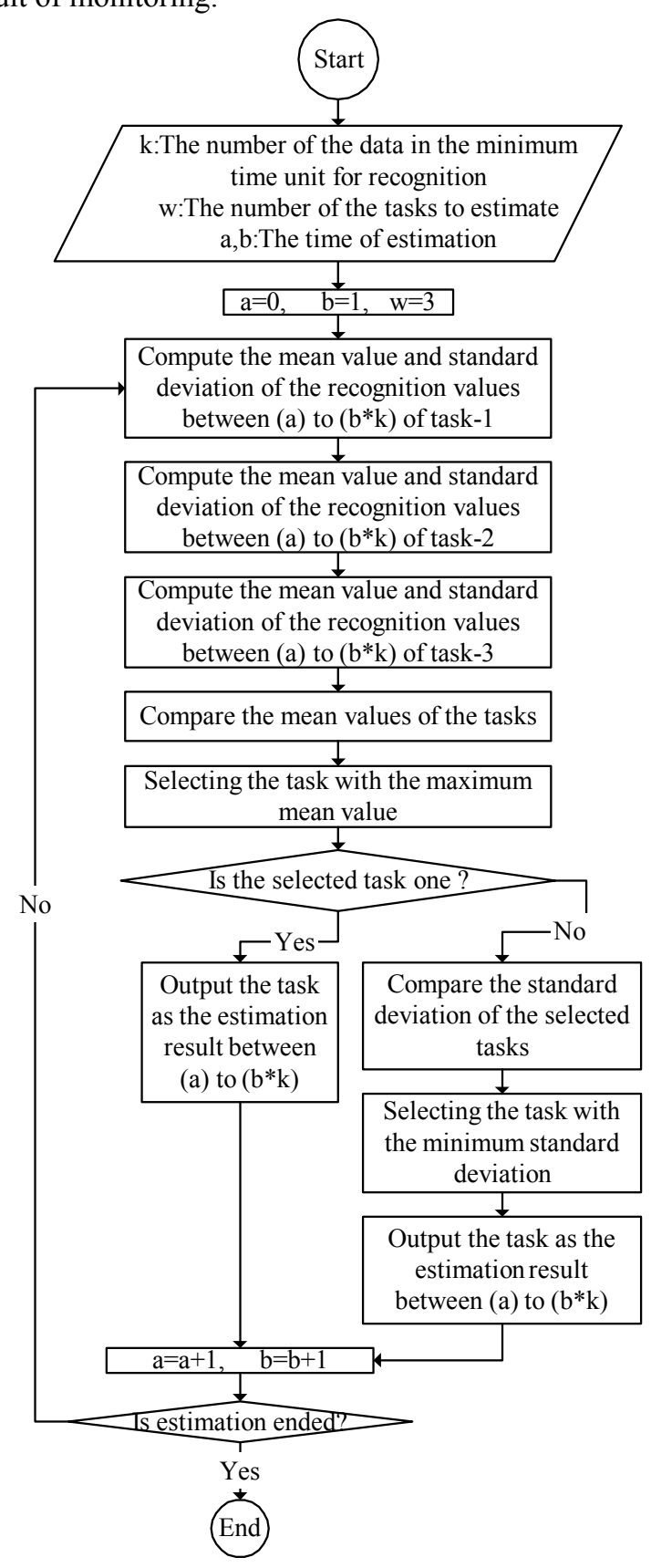

Figure 6. Task selecting flow

At the 1.5-second interval for selection of task, the mean values become the synthetic evaluation measure for estimation. Mean value is outputs neural for tasks in each time unit. The system selects the task as its estimating result, which has the maximum mean value.

When more than one maximum recognition values were found in the result, comparison of the mean values, the standard deviation for the mean value is adopted as evaluation value, and the estimation with minimum standard deviation is selected.

Estimation result of overall evaluation in the monitoring system is shown in Figure-6. First, recognition value for output neural in each time (between (a) to $\left(b^{*} k\right)$ ) is extracted. Mean value and standard deviation in each component task are computed from the recognition values. Next, estimation is decided from comparison of mean values in each time. The task with the maximum of mean value becomes the selection. When selection cannot be made for two or more result having the same, maximum mean values, and the task with the minimum standard deviation becomes selected.

\section{EXPERIMENTAL RESULTS}

\subsection{EVALUATION OF THE MONITORING SYSTEM}

The authors conducted experiment to evaluate performance of the monitoring system. Feature parameters for "Moving Panel", "Drilling", "Walking" are collected through from a sample worker equipped with the prototype. Then authors went though training of neural network with feature parameter gathered, and established monitoring system for three types of task.

For developing system, Visual Basic by Microsoft was used and estimated result is displayed in each 4.5 seconds as designed and in real time. Mobile computer with Pentium(R) M $1 \mathrm{Ghz}$ was used for data analysis.

In experiment, the worker repeated the 3 tasks for 3 times, taking approximately ten minutes. Estimated result was collected at the time. The result was compared to actual data derived from videotape in 0.1 second interval and showed that $97.5 \%$ agreed. From the result, the system proved to function well. The possible causes of errors were seen at the end of task. Because two feature parameters are included in a 1.5 second time unit.

\subsection{SUITABILITY OF THE MONITORING SYSTEM}

Suitability of the monitoring system trained with a worker's feature parameters to other workers who have different physical and working characteristics are also examined. Five different workers used the same monitoring system used in previous experiment performed the same three tasks and data was collected for each. As shown in Table-3, workers are male with their stature vary from $163 \mathrm{~cm}$ to $183 \mathrm{~cm}$. 
Table 3. Body dimension of workers

\begin{tabular}{c|c|c|c|c|c}
\hline \multirow{2}{*}{ Body Dimension } & \multicolumn{5}{|c}{ Worker } \\
\cline { 2 - 6 } & A & B & C & D & E \\
\hline Stature $(\mathrm{cm})$ & 164 & 183 & 174 & 179 & 176 \\
\hline Reach $(\mathrm{cm})$ & 160 & 182 & 174 & 177 & 175 \\
\hline Crotch Height $(\mathrm{cm})$ & 70 & 92 & 83 & 85 & 84 \\
\hline Weight $(\mathrm{kg})$ & 60 & 70 & 64 & 60 & 70 \\
\hline
\end{tabular}

As in Table-4, the system's estimation for these workers matched approximately $97 \%$ of actual tasks done.

Even the feature parameters were taken from the worker $\mathrm{A}$, the rates of matched from other four workers were over $96 \%$, proving that effect of workers physical characteristics and work pattern are remote and system functions effectively. Also feature parameter collected by monitoring system correctly figured out the characteristics of motion.

Table 4. Results of estimation

\begin{tabular}{|c|c|c|c|c|c|}
\hline \multirow[b]{2}{*}{ Worker } & \multirow[b]{2}{*}{ Index } & \multicolumn{3}{|c|}{ Work } & \multirow[b]{2}{*}{ Total } \\
\hline & & $\begin{array}{c}\text { Moving } \\
\text { Panel }\end{array}$ & Drilling & walking & \\
\hline \multirow{3}{*}{ A } & Time(sec.) & 179.4 & 164.0 & 239.9 & 583.3 \\
\hline & Matched Time(sec.) & 179.2 & 158.8 & 230.8 & 568.8 \\
\hline & Rate of Matched $(\%)$ & 99.9 & 96.8 & 96.2 & 97.5 \\
\hline \multirow{3}{*}{ B } & Time(sec.) & 184.2 & 145.6 & 221.2 & 550.9 \\
\hline & Matched Time(sec.) & 178.9 & 141.6 & 217.3 & 537.7 \\
\hline & Rate of Matched $(\%)$ & 97.1 & 97.3 & 98.2 & 97.6 \\
\hline \multirow{3}{*}{$\mathrm{C}$} & Time(sec.) & 165.6 & 140.0 & 228.6 & 534.2 \\
\hline & Matched Time(sec.) & 159.5 & 139.4 & 225.7 & 524.6 \\
\hline & Rate of Matched $(\%)$ & 96.3 & 99.6 & 98.7 & 98.2 \\
\hline \multirow{3}{*}{$\mathrm{D}$} & Time(sec.) & 159.1 & 147.1 & 245.1 & 551.3 \\
\hline & Matched Time(sec.) & 154.9 & 142.7 & 244.0 & 541.6 \\
\hline & Rate of Matched $(\%)$ & 97.4 & 97.0 & 99.5 & 98.2 \\
\hline \multirow{3}{*}{$\mathrm{E}$} & Time(sec.) & 185.9 & 151.3 & 207.9 & 545.2 \\
\hline & Matched Time(sec.) & 177.2 & 146.3 & 207.0 & 530.5 \\
\hline & Rate of Matched $(\%)$ & 95.3 & 96.7 & 99.6 & 97.3 \\
\hline
\end{tabular}

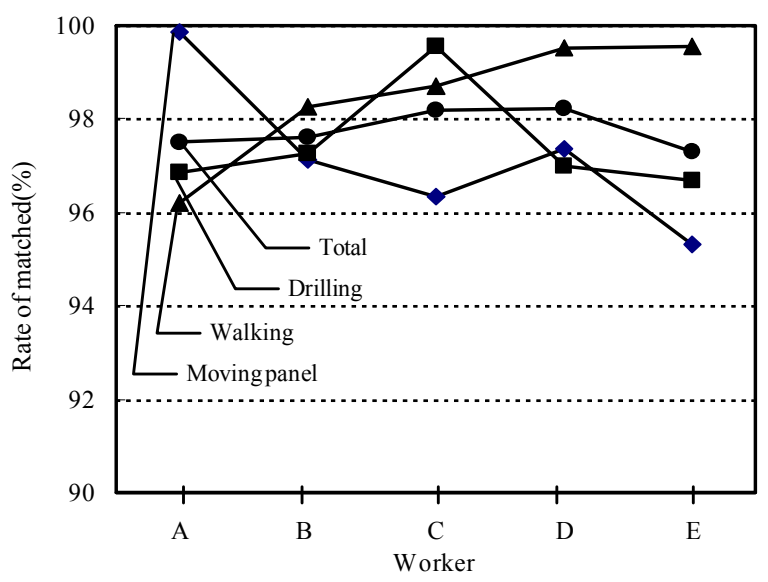

Figure 7. Rate of matched in each worker

Moreover, the relationship between percentage of each task for total working time and accuracy of the estimate is shown in Figure-8. As in figure, estimate of tasks which account more time such as "Walking" matches to actual work than the ones with less time, such as "Drilling" better, although the difference among them was within $4 \%$. The system proved to be efficient for estimating various tasks which rate of time is at least $25 \%$.

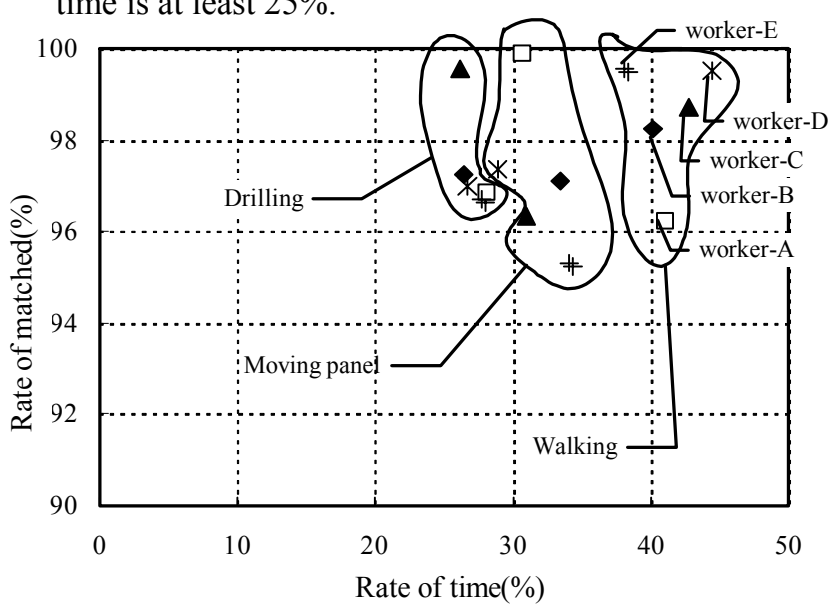

Figure 8. Relationship between rate of tasks for all working time and rate of matched

\section{CONCLUSION}

The authors developed monitoring system of data collection and utilization of 6-DOF motion sensor techniques in practical use.

Prototype was made based on the developed system and experiment was conducted. The result was compared to actual data and showed that $97.5 \%$ agreed. From the result, the system proved to function well. Moreover, the feature parameters were taken from a worker, the rates of matched from other four workers were over $96 \%$. From the result, the system proved that effect of workers physical characteristics and work pattern are remote and system functions effectively.

This monitoring system is expected to be a tool of supervising workers at the site from the remote site office, by obtaining the information to current work progress and work performance of each worker with 6-DOF sensors.

\section{REFERENCES}

[1] Yasushi Tamura, etc., "A study of rationalization in construction site", Proceeding of the 31th Architectural Research Meeting, Kanto Chapter, AIJ, pp49-52, Jan., 1963 [2] Naoto Mine, "A study on the proper management in concrete work" Waseda Univ., Science and Engineering ph.D. thesis, Mar., 1993

[3] Kenji Kobayasi, Yasushi Tamura, "Fatigue of works in highrise constructions", J. Archit. Plann. Environ. Eng., AIJ, No.476, pp. 145-153, Oct., 1995

[4] Naruo Kano, "Computer-aided Planning in construction evaluations of alternatives in construction planning", $17^{\text {th }}$ International symposium on automation and robotics in construction (ISARC), pp. 249-254, Sept., 2000

[5] Soungho Chae, Naruo Kano, "A study of estimation on building works", J. Archit. Plann. Environ. Eng., AIJ, No.564, pp. 295-302, Feb., 2003 